\title{
PENENTUAN PRIORITAS PENINGKATAN KUALITAS JASA DENGAN MENGGUNAKAN METODE IMPORTANCE-PERFORMANCE ANALYSIS (IPA) DAN INDEKS POTENTIAL GAIN CUSTOMER VALUE (PGCV)
}

\author{
Nur Hakim Arifianto, SauptikaKancana, \\ Adi Soeprapto \\ email : nurhakimarifianto0@gmail.com \\ Fakultas FISIP, Jurusan Administrasi Bisnis, \\ Universitas Pembangunan Nasional "Veteran" Yogyakarta \\ J1. Babarsari 2, Tambakbayan Yogyakarta 55281
}

\section{ABSTRACT}

The purpose of the research is (1) analyzing the level of conformity between expectations (importance) customer and performance (performance) of the company against the quality of services provided by Yamaha Motorcycle repair shop (2) Determine the priority Quality improvement based on the level of conformity and index of Potential Gain Customer Value (PGCV) to improve the quality of services provided by Yamaha Motorcycle repair shop.

The population in this research is a customer Yamaha Motorcycle repair shop Demangan Yogyakarta for approximately arround 2 months April 2019 till June 2019. Determination of the number of samples will be determined by the level of Confidance $95 \%$ and margin of error is $10 \%$ then obtained the number of samples as many as 98 people. The sampling techniques used in this study were based on Non Probabiliy Sampling methods using the Accidental Sampling approach.The results showed that (1) the level of conformity between expectations (importance) of the customer and performance (performance) of the company against the quality of services provided by the Yamaha Motorcycle repair shop Demangan Yogyakarta has an average level of conformity Below $100 \%$ of which is $88.30 \% .88 .30 \%$ means the company lacks or does not fulfill what is considered important by the customer and the service has not been satisfactory; (2) Priority of improvement of service quality (top priority in the Quadrant A IPA diagram with index PGCV) namely: 1) Workshop Yamaha new source Motor Demangan has a complete spare parts, 2) equipment used Yamaha Workshop new source Demangan complete, 3) Employees Yamaha Motorcycle repairshopDemangan tell the customers when the service is certainly motorbike will be delivered, 4) Employees Yamaha Motorcycle repair shop Demangan always ready in responding to customer demand, 5) Mechanics workshop Yamaha Motorcycle repair shop Demangan fast In servicing motorcycles, 6) Employees Yamaha Motorcycle repair shop Demangan always able to answer questions related to Yamaha motorcycles, 7) Employees Yamaha Motorcycle repair shop Demangan always prioritize the expectations of customers.

Keywords: Importance Performance Analysis (IPA),Potential Gain, Service Quality. 


\section{Pendahuluan}

Peningkatan kualitas jasa menjadi penting untuk mengimbangi harapan pelanggan. Harapan pelanggan mengenai kualitas jasa saat ini semakin tinggi dalam hal menilai suatu kualitas jasa yang diberikan oleh perusahaan penyedia jasa. Harapan yang tinggi disebabkan oleh semakin tingginya tingkat kesadaran tentang hak untuk memperoleh kualitas jasa yang baik, dalam lingkup penelitian ini adalah perusahaan penyedia jasa servis sepeda motor.

Perusahaan jasa servis sepeda motor yang dapat menyediakan kualitas jasa yang baik untuk dapat memenuhi harapan pelanggan sangatlah banyak di Yogyakarta sehingga memberikan berbagai alternatif bagi pelanggan. Banyaknya alternatif perusahaan penyedia jasa servis sepeda motor yang mampu memberikan kualitas jasa yang baik membuat harapan pelanggan terhadap jasa yang diberikan perusahaan cenderung akan semakin besar karena pelanggan akan membandingkan kinerja dari penyampaian suatu jasa dengan perusahaan pesaing. Salah satu perusahaan jasa servis sepeda motor yang dijadikan objek penelitian adalah Bengkel Yamaha Sumber Baru Motor Demangan yang merupakan salah satu dealer cabang resmi dari Yamaha Sumber Baru Motor yang ada di Yogyakarta.

Memang tidak mudah untuk menjadi yang terbaik agar memenangkan persaingan bisnis karena perusahaan harus dapat memberikan kualitas yang sesuai dengan kebutuhan dan dapat memenuhi harapan pelanggan. Kualitas jelas merupakan kunci untuk menciptakan nilai dan kepuasan pelanggan (Kotler, 2009:144). Kualitas memang memiliki hubungan yang erat dengan kepuasan pelanggan (Tjiptono, 2004:54). Kualitas memberikan suatu dorongan kepada pelanggan untuk menjalin ikatan yang kuat dengan perusahaan. Dalam jangka panjang, ikatan seperti ini memungkinkan untuk memahami dengan seksama harapan dan keutuhan pelanggan. Dengan demikan perusahaan dapat meningkatkan kepuasan pelanggan dimana perusahaan memaksimumkan pengalaman pelanggan yang menyenangkan dan meminimumkan pengalaman pelanggan atau meniadakan pengalaman yang kurang menyenangkan. Ukuran kualitas jasa bukan hanya ditentukan oleh pihak yang memberikan, tetapi juga 
oleh pihak yang menerimanya, yaitu pelanggan dikarenakan merekalah yang menikmati sehingga mereka dapat mengukur kualitas jasa berdasarkan harapan-harapan mereka dalam memenuhi kebutuhannnya.

Pelanggan memang harus dipuaskan, pelanggan yang tidak puas akan meninggalkan perusahaan dan menjadi pelanggan perusahaan lain yang dapat memberikan kepuasan yang lebih baik. Makin banyak pelanggan yang beralih menjadi pelanggan pesaing, dapat diramalkan bahwa hasil penjualan akan menurun dan pada giliranya laba juga akan turun (Supranto, 2011:2). Oleh karena itu, untuk mengetahui kebutuhan dan harapan pelanggan sangat penting bagi perusahaan.

Mengetahui apakah harapan pelanggan sudah terpenuhi dengan kinerja yang diberikan oleh perusahaan penyedia jasa sangatlah penting. Apabila kinerja dibawah harapan, maka pelanggan akan kecewa. Bila kinerja sesuai dengan harapan, pelanggan akan puas. Sedangkan bila kinerja melebihi harapan pelanggan akan sangat puas (Supranto, 2011:234). Dalam konsep ini kepuasan tidak diukur langsung, tetapi berdasarkan kesesuaian atau ketidaksesuaian antara harapan pelanggan dengan kinerja aktual perusahaan. Responden dapat diminta untuk me-ranking berbagai elemen (indikator) dari penawaran berdasarkan derajat pentingnya setiap elemen dan seberapa baik kinerja perusahaan dalam masing-masing elemen (importance/performance ratings).

Harapan pelanggan dapat diketahui dengan melakukan survei secara langsung terhadap pengguna jasa perusahaaan servis sepeda motor di Bengkel Yamaha Sumber Baru Motor Demangan Yogyakarta dengan menggunakan metode Importance Performance Analysis (IPA). Harapan dari hasil penelitian ini dapat dijadikan masukan dan rekomendasi bagi Bengkel Yamaha Sumber Baru Motor Demangan untuk membantu dalam menentukan strategi-strategi yang berorientasi pada peningkatan kualitas jasa terutama pada indikator yang dianggap penting bagi pelanggan namun kinerjanya masih dirasa kurang sehingga harapan pelanggan dapat terpenuhi.

Metode IPA digunakan untuk melihat tingkat kesesuaian antara kinerja (Performance) Bengkel Yamaha Sumber Baru Motor Demangandengan harapan 
(Importance) pelanggan terhadap kualitas jasa yang diberikan perusahaan. Hasil ratarata dari keseluruhan tingkat kesesuaian digunakan untuk mendapatkan cerminan dalam pemenuhan kepuasan pelanggan berdasarkan kriteria nilai tingkat kesesuaian pelanggan. Rata-rata skor kinerja dan harapan setiap indikator akan dijadikan titik koordinat untuk memetakan indikator kedalam diagram kartesius. Diagram kartesius membagi indikator ke dalam empat bagian, yaitu: kuadran A (Prioritas utama), kuadran B (Pertahankan prestasi), kuadran C (Prioritas Rendah) dan kuadran D (Berlebihan). Metode Indeks PGCV dijadikan sebagai jalan yang memberikan kemudahan bagi metode IPA untuk dapat dibandingkan dalam bentuk kuantitatif yang lebih terperinci dengan urutan indeks dari yang terbesar hingga yang terkecil.

Metode IPA petama kali dikenalkan oleh Martila dan James (1997). Isfarani (2011) dalam Sukwadi (2015) menjelaskan bahwa metode IPA ini memiliki kelebihan dibandingkan dengan metode yang lain, diantaranya adalah sebagai berikut:

1. Prosedur dari metode yang digunakan cukup sederhana.

2. Pengambilan kebijakan dapat dengan mudah menentukan prioritas kegiatan yang harus dilakukan dengan sumber daya yang terbatas.

3. Metode IPA cukup fleksibel untuk diterapkan pada berbagai bidang.

Metode selanjutnya yang digunakan dalam penelitian ini adalah metode PGCV yang pertama kali dikenalkan oleh William C. Hom (1997). Woodruff (1997) mengatakan bahwa nilai pelanggan merupakan preferensi yang dirasakan oleh pelanggan berdasarkan hasil evaluasi pelanggan terhadap indikator dimensi kualitas jasa.

Metode IPA dan PGCV dengan menggunakan dimensi kualitas jasa yang disampaikan Parasuraman (1998) diharapkan mampu memberikan hasil berkaitan dengan indikator yang secara prioritas harus ditingkatkan untuk memenuhi harapan pelanggan. Metode PGCV pernah digunakan dalam penelitian disalah satu cabang bank di Medan oleh Siregar (2006). Beliau berpendapat bahwa analasis pelanggan melalui Indeks PGCV merupakan konsep yang mudah untuk menganalisis pelanggan. Pendapat lainya disampaikan oleh Darmawan (2014) PGCV merupakan pelengkap dari metode 
IPA. Metode ini merupakan metode yang mudah dilakukan untuk menganalisi pelanggan. Kemudahan tersebut memberikan jalan bagi diagram kartesius IPA untuk dibandingkan dalam bentuk kuantitatif yang lebih terperinci. Metode PGCV dapat menganalisis masing-masing indikator yang diteliti. Kelebihan inilah yang dapat digunakan untuk melengkapi analisis IPA di mana metode tersebut hanya membagi indikator ke dalam bagian yang perlu diprioritaskan atau tidak.

Alasan peneliti mengambil objek penelitian bengkel sepeda motor berdasarkan pada tabel 1. tentang jumlah perkembangan kendaraan bermotor berdasarkan jenisnya tahun 2013 - 2017. Jumlah perkembangan kendaraan bermotor di Indonesia apabila dibandingkan pada tahun 2017 dengan tahun 2016 terjadi kenaikan pada semua jenis kendaraan bermotor. Jenis kendaraan yang mengalami pertumbuhan tertinggi adalah mobil penumpang sebesar $7,7 \%$, disusul dengan mobil truk dengan pertumbuhan sebesar 7,59\%, kemudian sepeda motor dengan pertumbuhan sebesar 7,47\% dan terakhir adalah bis dengan pertumbuhan sebesar 2,35\%. Namun untuk jumlah unit kendaraan bermotor terbanyak adalah sepeda motor dengan 113.030.793 unit apabila dibandingkan dengan jenis kendaraan bermotor lainya.

Tabel 1.

Jumlah Perkembangan Sepeda Motor Tahun 2013 - 2017

\begin{tabular}{|l|r|r|r|r|r|}
\hline Jumlah Kendaraan Bermotor & 2013 & 2014 & 2015 & 2016 & 2017 \\
\hline Mobil Penumpang & 11484514 & 12599038 & 13480973 & 14580666 & 15493068 \\
\hline Mobil Bis & 2286309 & 2398846 & 2420917 & 2486898 & 2509258 \\
\hline Mobil Barang & 5615494 & 6235136 & 6611028 & 7063433 & 7523550 \\
\hline Sepeda Motor & 84732652 & 92976240 & 98881267 & 105150082 & 113030793 \\
\hline Jumlah & 104118969 & 114209260 & 121394185 & 129281079 & 138556669 \\
\hline
\end{tabular}

Sumber: www.bps.go.id

Saat ini jumlah bengkel yang ada di Yogyakarta semakin banyak jumlahnya. Banyaknya bengkel yang ada dikarenakan adanya kebutuhan jasa servis sepeda motor. Servis yang dilakukan pada sepeda motor sangatlah penting. Sepeda motor haruslah tetap pada keadaan yang prima agar dapat memudahkan masyarakat dalam kegiatan 
mobilisasi sehari-hari. Bengkel yang dapat memenuhi harapan pelanggan sangatlah banyak sehingga memberikan berbagai alternatif bagi pelanggan. Alternatif yang banyak membuat persaingan antar bengkel resmi maupun tidak resmi semakin ketat.

Berdasarkan catalog sensus data eknonomi tahun 2016-lanjutan yang diperoleh dari Badan Pusat Statistik (BPS) tentang publikasi hasil yang menggambarkan karakterisktik usaha sektor dari segi aktivitas eknominya yaitu perdagangan besar dan eceran; servis mobil dan sepeda motor yang termasuk dalam kategori G. Data yang dimuat pada publikasi tersebut menyatakan bahwa di Provinsi Yogyakarta terdapat 13.217 unit Bengkel yang terdiri dari usaha kecil menengah hingga besar. Persentase apabila dilihat dari skala nasional berdasarkan bentuk badan usahanya yang dinyatakan dalam tabel 2. adalah sebagai berikut:

Tabel 2.

Karakterisktik Usaha Sektor G

\begin{tabular}{|l|l|}
\hline \multicolumn{1}{|c|}{ Bentuk Badan Usaha } & \multicolumn{1}{c|}{ Persentase (\%) } \\
\hline Persero & $0,61 \%$ \\
\hline Izin Khusus & $3,91 \%$ \\
\hline CV & $0,62 \%$ \\
\hline Badan Usaha & $0,29 \%$ \\
\hline Tidak Berbadan Usaha & $94,57 \%$ \\
\hline
\end{tabular}

Sumber: www.bps.co.id

Salah satu bengkel berbadan usaha adalah bengkel resmi milik Yamaha Sumber Baru Demangan Motor yang merupakan bengkel cabang dari Yamaha Sumber Baru Motor. Penelti mengambil ulasan dari situs (https://maps.google.com/) untukmengetahui kepentingan (importance) pelanggan dan kinerja (performance) terhadap Bengkel Yamaha Sumber Baru Motor Demangan yang peneliti rangkum menjadi tabel 1.3 sebagai berikut: 
Tabel 3.

Ulasan Pelanggan

\begin{tabular}{|l|l|}
\hline \multicolumn{1}{|c|}{ Nama } & \multicolumn{1}{|c|}{ Permasalahan } \\
\hline Nanang Peang & $\begin{array}{l}\text { Pelayanan terburuk dealer yamaha dijogja... Servis motor dari jam 10 } \\
\text { pagi jam 1 belum kelar kalo gak niat buka mbok tutup aja sangat } \\
\text { kecewa...sudah tercantum nomer telvon gak dihubungi sama sekali } \\
\text { kalo motornya belum dikerjain...jangan sekali kali nyoba servis } \\
\text { motor disini...pasti bakal kecewa Masih mending diBengkel pinggir } \\
\text { jalanan yg lebih baik melayani customer. }\end{array}$ \\
\hline Reza Dewantara & $\begin{array}{l}\text { Mekanik kurang berpengalaman. Injector rusak vonisnya fuel pump } \\
\text { rusak. Ketika claim malah nyalahin openlooper ku rusak, ketika } \\
\text { dibawa ke Bengkel lain ternyata injector. Harap hati hati }\end{array}$ \\
\hline Reza Hendra & $\begin{array}{l}\text { Tempat yang bagus dengan pelayanan yang sangat ramah, memiliki } \\
\text { peraturan mengenai hak konsumen yang mana konsumen merasa } \\
\text { seperti raja. Ruang tunggu yang sangat nyaman dikala anda } \\
\text { melakukan servis pada motor anda. Intinya "Yamaha Semakin } \\
\text { Didepan!!" }\end{array}$ \\
\hline Rama Dhan & $\begin{array}{l}\text { Pelayanan di sini ramah, tetapi antri nya agak lama, pengerjaan } \\
\text { beberapa motor dikerjain dengan 1 teknisi saja dan saat siang barulah } \\
\text { teknisinya pada datang, tempat tunggunya sangat luas dan juga sepi. } \\
\text { Jadi nunggu sambil tidur juga bisa. }\end{array}$ \\
\hline fahrul ahmad & $\begin{array}{l}\text { Kurang baik pelayanan oke tapi proses pengerjaannya lama banget } \\
\text { ngantri 1 motor sampai nunggu 2jaman, 3jaman baru selesai dengan } \\
\text { kondisi dealer sepi }\end{array}$ \\
\hline Mekaniknya komunikatif. Enak diajak diskusi. Tidak harus langsung \\
ganti kerusakan.
\end{tabular}

Sumber: https://maps.google.com 
Ulasan mengenai harapan pelanggan terhadap kinerja Bengkel Yamaha Sumber Baru Motor Demangan yang peneliti rangkum pada tabel 1.3 merupakan permasalahan yang yang terjadi karenanya adanya kesenjangan antara harapan (importance) pelanggan dan kinerja (performance) perusahaan terhadap kualitas jasa yang diberikan oleh Bengkel Yamaha Sumber Baru Demangan Motor.

Memang tidak semua ulasan yang disampaikan pada tabel 3 tidak selalu negatif, ada pula pelanggan yang memberikan ulasan positif karena harapanya terpenuhi. Pelanggan pada dasarnya menilai suatu kualitas jasa berbeda-beda. Perbedaan tersebut bisa berdasarkan preferensi pelanggan yang memiliki kecenderungan berbeda dalam menilai indikator suatu kualitas jasa.

Perbedaan tersebut dapat dicontohkan seperti harapan pelanggan yang muncul karena masing-masing kebutuhan pribadi seseorang terhadap jasa berbeda seperti kebutuhan fisik, sosial, dan psikologis. Pemikiran ini dilandasi oleh apa yang dikatakan Woodruff (1997) bahwa pelanggan memiliki preferensi yang berbeda dalam menilai suatu kualitas jasa dan berdasarkan hasil penelitian Parasuraman, et al. (1993) dalam Tjiptono (2011:187) tentang faktor-faktor apa saja yang membentuk harapan.

Peneliti memilih lokasi penelitian di Bengkel Yamaha Sumber Baru Motor Demangan didasari karena peneliti telah melakukan pra survey sebagai pelanggan Bengkel tersebut. Peneliti melakukan observasi serta merasakan bahwa Bengkel Yamaha Sumber Baru Motor Demangan cenderung sepi bila dibandingkan dengan Bengkel Yamaha Sumber Baru Motor lainya. Sepinya pengunjung dapat diperkirakan karena gagalnya bersaing dengan Bengkel Yamaha Sumber Baru Motor lainya dalam memenuhi harapan pelanggan kinerja yang diberikan terhadap kualitas jasa dan juga kurangnya memahami indikator yang dianggap penting bagi pelanggan untuk ditingkatkan kualitas jasanya agar harapan pelanggan dapat terpenuhi. Pernyataan ini dukung dengan total rating yang peneliti ambil dari www.google.com dan peneliti rangkum pada tabel 4 sebagai berikut: 
Tabel 4.

Total Rating Bengkel Yamaha Sumber Baru Motor Yogyakarta

\begin{tabular}{|l|l|c|}
\hline Nama Bengkel & Lokasi Bengkel & Rating \\
\hline Sentral1 Yamaha Yogya & J1. P. mangkubumi No.27 & 4,6 \\
\hline Yamaha Sumber Baru Motor 133 & J1. Magelang No.133 & 4,3 \\
\hline Yamaha Sumber Baru Motor & J1. Brigjen Katamso No.104 & 4,2 \\
\hline Yamaha Sumber Baru Motor & J1. Kusumanegara No.102 & 4,1 \\
\hline Yamaha Sumber Baru Pingit & J1. Pangeran Diponegoro & 4,0 \\
\hline Yamaha Sumber Demangan & J1. Laksda Adisucipto No.14 & 3,9 \\
\hline
\end{tabular}

Sumber: Data diolah oleh peneliti

Pada tabel 1.4 menunjukan bahwa Bengkel Yamaha Sumber Baru Motor Demangan memiliki total rating yang rendah apabila dibandingkan dengan Bengkel Sumber Baru Motor Yogyakarta lainya. Total rating yang rendah menjadi ketertarikan peneliti untuk melakukan penelitian di Bengkel Yamaha Sumber Baru Motor Demangan.

Alasan lain yang membuat peneliti tertarik melakukan penelitian tentang kualitas jasa dikarenakan penyampaian jasa yang kerap kali tidak konsisten karena unsur jasa sendiri yang bersifat variability. Sebagai contoh, dua orang yang datang ke sebuah salon dan meminta model rambut serupa tidak mungkin mendapatkan hasil yang seratus persen identik (kecuali kalau keduanya minta rambutnya di plontos). Hal semacam ini terjadi karena melibatkan unsur manusia dalam proses produksi dan konsumsinya. Berbeda dengan mesin, orang biasanya tidak bisa diprediksi dan cenderung tidak konsisten dalam hal sikap dan perilakunya.

Berdasarkan uraian tersebut, maka penulis tertarik untuk melakukan penelitian tentang peningkatan kualitas jasa di Bengkel Yamaha Sumber Baru Motor Demangan. Dengan menganalisis tingkat kesesuaian antara harapan (importance) pelanggan dengan kinerja (performance), maka dapat diketahui sejauh mana tingkat kinerja yang diharapkan oleh pelanggan terhadap kualitas jasa yang mereka peroleh. Indikator yang ada pada kuisioner selanjutnya akan dirata-rata skor perolehanya kemudian akan dipetakan menggunakan diagram kartesius sehingga dapat diketahui indikator apa saja 
yang perlu ditingkatkan, dipertahankan, dikurangi, dan indikator yang tidak terlalu penting bagi pelanggan.

Penggunaan metode PGCV dapat diketahui indikator mana yang secara prioritas harus ditingkatkan untuk memenuhi harapan pelanggan secara kuantitatif. Hasil penelitian ini diharapkan dapat menjadi masukan dan evaluasi bagi perusahaan untuk membantu menentukan strategi-strategi yang lebih berorientasi pada peningkatan kualitas jasa sehingga harapan pelanggan dapat terpenuhi agar dapat memenangkan persaingan di kategori penyedia jasa servis sepeda motor oleh Bengkel Yamaha Baru Sumber Baru Motor Demangan.

\section{MetodePenelitian}

Obyek dalam penelitian ini adalah Bengkel Yamaha Sumber Baru Motor Demangan Yogyakarta. Populasi dalam penelitian ini adalah Pelanggan Bengkel Yamaha Sumber Baru Motor Demangan Yogyakarta selama kurang lebih 2 bulan yaitu bulan April -Juni 2019. Penentuan jumlah sampel akan ditentukan dengan level of confidance 95\% dan margin of error sebesar $10 \%$ maka didapatkan jumlah sampel sebanyak 98 orang. Teknik penentuan sampel yang digunakan pada penelitian ini adalah didasarkan pada metode Non Probabiliy Sampling dengan menggunakan pendekatan Accidental Sampling.

Kuesioner terbagi menjadi dua bagian besar. Bagian pertama berisi pernyataan mengenai data demografi responden. Bagian kedua berisi 21 pernyataan yang berkaitan dengan kualitas jasa yang disediakan oleh pihak Bengkel. Pada bagian ini, respondendiminta memilih satu dari lima pilihan jawaban yang di- tuliskan dalam skala pengukuran Likert 1 sampai 5, masingmasing menunjukkan sangattidak baik (1) sampai sangat baik (5) (untuk menilai tingkat kinerja) serta sangat tidak penting (1) sampai sangat penting (5) (untuk menilai tingkat kepentingan) dari setiap pernyataan dalam kuesioner. Sebanyak 98 kuesioner disebarkan secara langsung. 


\section{Hasil dan Pembahasan}

\subsection{Profil Responden}

Karakteristik Responden Bengkel Yamaha Sumber Baru Motor Demangan dapat dilihat pada tabel 5 sebagai berikut:

Tabel 5.

Karakteristik Responden

\begin{tabular}{|c|c|c|c|}
\hline \multicolumn{2}{|c|}{ Karakteristik } & \multicolumn{2}{|c|}{ Jumlah } \\
\hline \multirow{2}{*}{ Jenis Kelamin } & Pria & 63 & $65 \%$ \\
\hline & Wanita & 35 & $35 \%$ \\
\hline \multirow{8}{*}{ Umur } & $\leq 21$ tahun & 25 & $25,5 \%$ \\
\hline & $21<\mathrm{x} \leq 25$ tahun & 23 & $23,5 \%$ \\
\hline & $25<\mathrm{x} \leq 29$ tahun & 22 & $22,4 \%$ \\
\hline & $29<\mathrm{x} \leq 33$ tahun & 8 & $2,2 \%$ \\
\hline & $33<\mathrm{x} \leq 37$ tahun & 9 & $9,2 \%$ \\
\hline & $37<\mathrm{x} \leq 41$ tahun & 7 & $7,1 \%$ \\
\hline & $41<\mathrm{x} \leq 45$ tahun & 4 & $4,1 \%$ \\
\hline & $45<\mathrm{x} \leq 49$ tahun & 0 & $0 \%$ \\
\hline \multirow{6}{*}{$\begin{array}{l}\text { Pendidikan } \\
\text { Terakhir }\end{array}$} & SMP & 25 & $26 \%$ \\
\hline & SMA & 44 & $45 \%$ \\
\hline & Diploma & 6 & $6 \%$ \\
\hline & S1 & 21 & $21 \%$ \\
\hline & S2 & 2 & $2 \%$ \\
\hline & S3 & 0 & $0 \%$ \\
\hline \multirow{5}{*}{$\begin{array}{c}\text { Pengeluaran } \\
\text { Biaya Servis } \\
\text { Rutin }\end{array}$} & $\mathrm{Rp}<20.000$ & 9 & $9 \%$ \\
\hline & Rp 20.000 - Rp 50.000 & 18 & $18 \%$ \\
\hline & Rp 50.001 - Rp 100.000 & 56 & $57 \%$ \\
\hline & Rp $100.001-\operatorname{Rp} 200.000$ & 12 & $12 \%$ \\
\hline & $\mathrm{Rp}>200.000$ & 3 & $3 \%$ \\
\hline \multirow{5}{*}{$\begin{array}{c}\text { Banyaknya } \\
\text { melakukan servis }\end{array}$} & 1 & 8 & $8 \%$ \\
\hline & 2 & 13 & $13 \%$ \\
\hline & 3 & 58 & $59 \%$ \\
\hline & 4 & 14 & $14 \%$ \\
\hline & 5 & 5 & $5 \%$ \\
\hline
\end{tabular}

Sumber: Data diolah oleh peneliti 


\subsection{Tingkat Kesesuaian dan Diagram IPA}

Tingkat kesesuaian yang dapat dihitung dari hasil indikator kinerja dibandingkan dengan tingkat kepentingan dari pelanggan. Hasilnya dapat dilihat pada Tabel 6 sebagai berikut:

Tabel 6.

Tingkat Kesesuaian Importance-Performance

Bengkel Yamaha Sumber Baru Motor Demangan

\begin{tabular}{|c|c|c|c|c|c|c|}
\hline $\mathrm{NO}$ & INDIKATOR & $\mathrm{Yi}$ & $\mathrm{Xi}$ & $\overline{\mathrm{y}}$ & $\overline{\mathrm{x}}$ & TKI \% \\
\hline 1 & $\begin{array}{l}\text { Mekanik Bengkel Yamaha Sumber } \\
\text { Baru Demangan mampu } \\
\text { memberikan jasa servis sepeda } \\
\text { motor sesuai dengan standar yang } \\
\text { dijanjikan. } \\
\end{array}$ & 416 & 397 & 4,24 & 4,05 & 95,43 \\
\hline 2 & $\begin{array}{l}\text { Mekanik Bengkel Yamaha Sumber } \\
\text { Baru Demangan mampu menyervis } \\
\text { sesuai pada masalah sepeda motor } \\
\text { pelanggan. }\end{array}$ & 427 & 384 & 4,36 & 3,92 & 89,93 \\
\hline 3 & $\begin{array}{l}\text { Mekanik Bengkel Yamaha Sumber } \\
\text { Baru Demangan mampu melakukan } \\
\text { servis sepeda motor sesuai dengan } \\
\text { waktu yang dijanjikan. }\end{array}$ & 410 & 360 & 4,18 & 3,67 & 87,80 \\
\hline 4 & $\begin{array}{l}\text { Bengkel Yamaha Sumber Baru } \\
\text { Demangan selalu mengupayakan } \\
\text { pencatatan (records) sesuai dengan } \\
\text { permintaan pelanggan yang bebas } \\
\text { dari kesalahan. }\end{array}$ & 415 & 375 & 4,23 & 3,83 & 90,36 \\
\hline & RATA-RATA REALIBILITAS & 1668 & 1516 & 4,26 & 3,87 & 90,89 \\
\hline 5 & $\begin{array}{l}\text { Karyawan Bengkel Yamaha } \\
\text { Sumber Baru Demangan } \\
\text { memberitahu pelangganya kapan } \\
\text { pastinya jasa servis sepeda motor } \\
\text { akan disampaikan. }\end{array}$ & 429 & 354 & 4,38 & 3,61 & 82,52 \\
\hline 6 & $\begin{array}{l}\text { Mekanik Bengkel Yamaha Sumber } \\
\text { Baru Demangan cepat dalam } \\
\text { menyervis sepeda motor. }\end{array}$ & 423 & 362 & 4,32 & 3,69 & 85,58 \\
\hline 7 & $\begin{array}{l}\text { Ketika pelanggan membutuhkan } \\
\text { sesuatu, karyawan Bengkel Yamaha } \\
\text { Sumber Baru Demangan selalu } \\
\text { bersedia untuk membantu } \\
\text { pelanggan. }\end{array}$ & 413 & 401 & 4,21 & 4,09 & 97,09 \\
\hline 8 & $\begin{array}{l}\text { Karyawan Bengkel Yamaha } \\
\text { Sumber Baru Demangan selalu siap } \\
\text { dalam merespon permintaan } \\
\text { pelanggan. }\end{array}$ & 415 & 349 & 4,23 & 3,56 & 84,10 \\
\hline \multicolumn{2}{|r|}{ RATA-RATA DAYA TANGGAP } & 1680 & 1466 & 4,29 & 3,74 & 87,26 \\
\hline 9 & $\begin{array}{l}\text { Perilaku karyawan Bengkel } \\
\text { Yamaha Sumber Baru Demangan } \\
\text { mampu membuat saya } \\
\text { mempercayai mereka. }\end{array}$ & 429 & 370 & 4,38 & 3,78 & 86,25 \\
\hline
\end{tabular}




\begin{tabular}{|c|c|c|c|c|c|c|}
\hline $\mathrm{NO}$ & INDIKATOR & $\mathrm{Yi}$ & $\mathrm{Xi}$ & $\overline{\mathrm{y}}$ & $\overline{\mathrm{x}}$ & TKI \% \\
\hline 10 & $\begin{array}{l}\text { Saya merasa aman dalam } \\
\text { melakukan servis sepeda motor di } \\
\text { Bengkel Yamaha Sumber Baru } \\
\text { Demangan. }\end{array}$ & 415 & 380 & 4,23 & 3,88 & 91,57 \\
\hline 11 & $\begin{array}{l}\text { Karyawan Bengkel Yamaha } \\
\text { Sumber Baru Demangan senantiasa } \\
\text { bersikap sopan terhadap para } \\
\text { pelangganya. }\end{array}$ & 409 & 365 & 4,17 & 3,72 & 89,24 \\
\hline 12 & $\begin{array}{l}\text { Karyawan Bengkel Yamaha } \\
\text { Sumber Baru Demangan senantiasa } \\
\text { mampu menjawab pertanyaan } \\
\text { terkait dengan sepeda motor } \\
\text { Yamaha. }\end{array}$ & 415 & 361 & 4,23 & 3,68 & 86,99 \\
\hline \multicolumn{2}{|r|}{ RATA-RATA JAMINAN } & 1668 & 1476 & 4,26 & 3,77 & 88,49 \\
\hline 13 & $\begin{array}{l}\text { Karyawan Bengkel Yamaha } \\
\text { Sumber Baru Demangan } \\
\text { memberikan perhatian secara } \\
\text { perseorangan kepada para } \\
\text { pelangganya. }\end{array}$ & 368 & 368 & 3,76 & 3,76 & 100,00 \\
\hline 14 & $\begin{array}{l}\text { Karyawan Bengkel Yamaha } \\
\text { Sumber Baru Demangan sungguh- } \\
\text { sungguh dalam memberikan } \\
\text { perhatian personal kepada para } \\
\text { pelangganya. }\end{array}$ & 385 & 328 & 3,93 & 3,35 & 85,19 \\
\hline 15 & $\begin{array}{l}\text { Karyawan Bengkel Yamaha } \\
\text { Sumber Baru Demangan Motor } \\
\text { selalu mengutamakan harapan para } \\
\text { pelanggan. }\end{array}$ & 414 & 362 & 4,22 & 3,69 & 87,44 \\
\hline 16 & $\begin{array}{l}\text { Karyawan Bengkel Yamaha } \\
\text { Sumber Motor Demangan } \\
\text { memahami kebutuhan spesifik para } \\
\text { pelangganya. }\end{array}$ & 398 & 357 & 4,06 & 3,64 & 89,70 \\
\hline 17 & $\begin{array}{l}\text { Bengkel Yamaha Sumber Motor } \\
\text { Demangan memiliki jam operasi } \\
\text { yang nyaman bagi semua } \\
\text { pelanggan. }\end{array}$ & 404 & 368 & 4,12 & 3,76 & 91,09 \\
\hline \multicolumn{2}{|r|}{ RATA-RATA EMPATI } & 1969 & 1783 & 4,02 & 3,64 & 90,55 \\
\hline 18 & $\begin{array}{l}\text { Peralatan yang digunakan Bengkel } \\
\text { Yamaha Sumber Baru Demangan } \\
\text { lengkap. }\end{array}$ & 426 & 350 & 4,35 & 3,57 & 82,16 \\
\hline 19 & $\begin{array}{l}\text { Ruang tunggu yang dimiliki } \\
\text { Bengkel Yamaha Sumber Motor } \\
\text { Demangan bersih. }\end{array}$ & 406 & 349 & 4,14 & 3,56 & 85,96 \\
\hline 20 & $\begin{array}{l}\text { Kerapian penampilan karyawan } \\
\text { Bengkel Yamaha Sumber baru } \\
\text { Demangan. }\end{array}$ & 381 & 367 & 3,89 & 3,74 & 96,33 \\
\hline 21 & $\begin{array}{l}\text { Bengkel Yamaha Sumber Baru } \\
\text { Motor Demangan memiliki } \\
\text { sparepart lengkap. }\end{array}$ & 431 & 317 & 4,40 & 3,23 & 73,55 \\
\hline & RATA-RATA BUKTI FISIK & 1644 & 1383 & 4,19 & 3,53 & 84,12 \\
\hline & RATA-RATA $\bar{x}$ dan $\bar{I}$ & & & 4,19 & 3,70 & 88,35 \\
\hline
\end{tabular}

Sumber: Data diolah oleh peneliti 
Hasil pemetaan nilai kinerja atau kepuasan terhadap suatu indikator dan nilai kepentingannya dapat dilihat pada diagram IPA (Gambar 1) sebagai berikut:

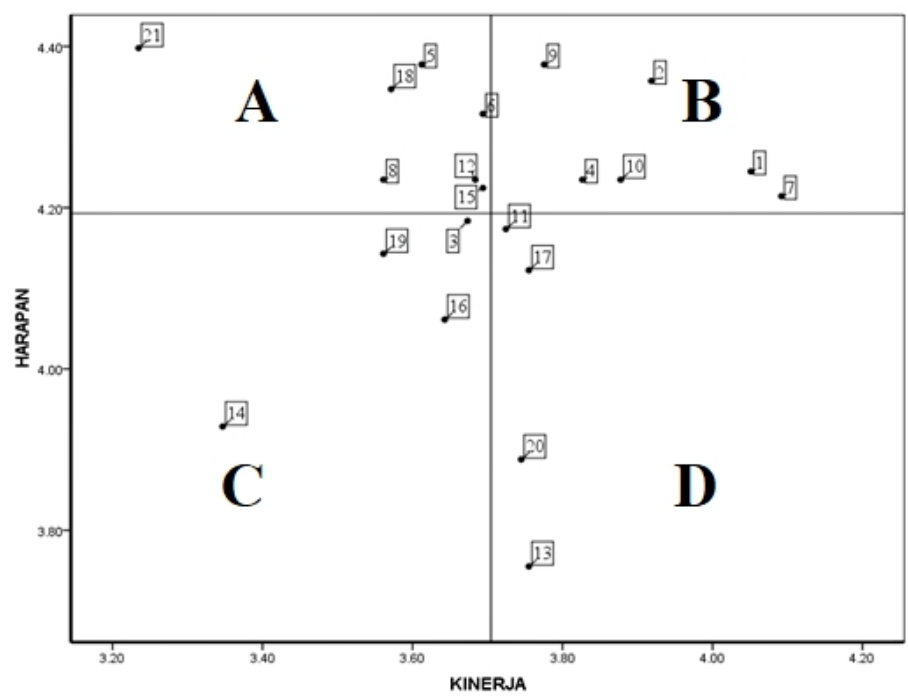

Sumber: Data diolah oleh peneliti

\section{Gambar 1.}

\section{Diagram Kartesius Importance- Performance}

Keterangan:

A (Prioritas Utama): Harapan Tinggi dan Kinerja Rendah

B (Pertahankan Prestasi): Harapan Tinggi dan Kinerja Tinggi

C (Prioritas Rendah): Harapan Rendah dan Kinerja Rendah

D (Berlebihan): Harapan Rendah dan Kinerja Tinggi

Pada Gambar 1 dapat dilihat bahwa indikator-indikator terbagi ke dalam empat kuadran. Kuadran A yang menjadi prioritas utama terdiri atas indikator nomor $21,18,5,8,6,12$, dan15. Kuadran A menjadi prioritas perbaikan oleh pihak Bengkel Yamaha Sumber Baru Motor Demangan Yogyakarta dengan segera. Kuadran B yang menjadi prestasi yang harus dipertahankan yaitu Indikator nomor 1, 2, 9, 4, 10, dan 7. Indikator ini menunjukan bahwa Bengkel Yamaha Sumber Baru Motor Demangan telah memberikan kualitas jasa sesuai dengan harapan konsumen. Kuadran $\mathrm{C}$ yang menjadi prioritas rendah yaitu indikator nomor 19, 16, 14, dan 3. Indikator pada kuadran ini menunjukan bahwa pihak Bengkel Yamaha Sumber Baru Motor Demangan dapat melakukan perbaikan untuk meningkatkan kualitas jasaBengkel. Kuadran D terdiri atas 
indikator nomor $11,17,20$, dan 13. Indikator kualitas jasa yang diberikan oleh pihak Bengkel Yamaha Sumber Baru Motor Demangan pada kuadran ini melebihi harapan dari pelanggan.

\subsection{Penentuan Indeks PGCV}

Nilai Achieve Customer Value (ACV) menunjukan besarnya nilai kualitas jasa yang diterima menurut sudut pandang pelanggan. Jika nilai ACV semakin besar maka ini berarti bahwa kualitas pelayanan pihak Bengkel Yamaha Sumber Baru Motor Demangan Yogyakarta semakin baik dari sudut pandang pelanggan, berlaku hal sebaliknya. Sedangkan, nilai UD CV meru pakan nilai akhir yang diinginkan penumpang. Indeks PGCV menunjukan selisih dari nilai yang diharapkan oleh penumpang dengan nilai yang diperoleh penumpang. Hal ini berarti bahwa semakin besar nilai indeks PGCV maka penumpang merasa kurang puas sehingga Indikator tersebut harus dilakukan peningkatan. Nilai indeks ini digunakan untuk menentukan indikator mana saja yang berpotensi paling besar dalam memberikan nilai tambah kualitas atau keuntungan. Tabel 7 menyajikan hasil perhitungan indeks PGCV.

Tabel 7.

Urutan Perhitungan Indeks PGCV

\begin{tabular}{|c|r|r|r|r|r|}
\hline \multirow{2}{*}{$\begin{array}{c}\text { INDIKAT } \\
\text { OR }\end{array}$} & $\begin{array}{c}\text { Nilai rata- } \\
\text { rata Tingkat } \\
\text { Kinerja }\end{array}$ & $\begin{array}{c}\text { Nilai rata- } \\
\text { rata Tingkat } \\
\text { kepentingan }\end{array}$ & Nilai ACV & \multicolumn{1}{c|}{$\begin{array}{c}\text { Nilai } \\
\text { UDCV }\end{array}$} & Nilai PGCV \\
\cline { 2 - 6 } & $(\mathrm{X})$ & $(\mathrm{Y})$ & $(\mathrm{X}) \mathrm{x}(\mathrm{Y})$ & $\begin{array}{c}(\mathrm{Y}) \mathrm{x} \\
(\mathrm{Xmax})\end{array}$ & $\begin{array}{c}\text { UDVC }- \\
\text { ACV }\end{array}$ \\
\hline P21 & 3,23 & 4,40 & 14,23 & 21,99 & 7,76 \\
\hline P14 & 3,35 & 3,93 & 13,15 & 19,64 & 6,49 \\
\hline P18 & 3,57 & 4,35 & 15,52 & 21,73 & 6,21 \\
\hline P8 & 3,56 & 4,23 & 15,08 & 21,17 & 6,09 \\
\hline P5 & 3,61 & 4,38 & 15,81 & 21,89 & 6,07 \\
\hline P19 & 3,56 & 4,14 & 14,75 & 20,71 & 5,96 \\
\hline P6 & 3,69 & 4,32 & 15,94 & 21,58 & 5,64 \\
\hline P12 & 3,68 & 4,23 & 15,60 & 21,17 & 5,57 \\
\hline
\end{tabular}




\begin{tabular}{|c|r|r|r|r|r|}
\hline P3 & 3,67 & 4,18 & 15,37 & 20,92 & 5,55 \\
\hline P15 & 3,69 & 4,22 & 15,60 & 21,12 & 5,52 \\
\hline P16 & 3,64 & 4,06 & 14,79 & 20,31 & 5,51 \\
\hline P9 & 3,78 & 4,38 & 16,53 & 21,89 & 5,36 \\
\hline P11 & 3,72 & 4,17 & 15,54 & 20,87 & 5,32 \\
\hline P17 & 3,76 & 4,12 & 15,48 & 20,61 & 5,13 \\
\hline P4 & 3,83 & 4,23 & 16,20 & 21,17 & 4,97 \\
\hline P20 & 3,74 & 3,89 & 14,56 & 19,44 & 4,88 \\
\hline P10 & 3,88 & 4,23 & 16,42 & 21,17 & 4,75 \\
\hline P2 & 3,92 & 4,36 & 17,07 & 21,79 & 4,71 \\
\hline P13 & 3,76 & 3,76 & 14,10 & 18,78 & 4,67 \\
\hline P1 & 4,05 & 4,24 & 17,20 & 21,22 & 4,03 \\
\hline P7 & 4,09 & 4,21 & 17,24 & 21,07 & 3,83 \\
\hline
\end{tabular}

Sumber: Data diolah oleh peneliti

\subsection{Penentuan Prioritas Perbaikan Atribut Layanan}

Sesuai dengan konsep diagram IPA, focus peningkatan kualitas jasa dilakukan terhadap pihak Bengkel Yamaha Sumber Baru Motor Demangan yaitu pada indikator-indikator yang berada dalam kuadran A. Adapun penentuan prioritas berdasarkan tingkat keesuaian dan nilai indeks PGCV. Indikator dengan prioritas peningkatan pertama apabila memiliki tingkat kesesuaian terendah dan nilai indeks PGCV tertinggi.

Tabel 8.

Urutan Prioritas Perbaikan Kualitas Jasa Berdasarkan Hasil IPA Dan PGCV

\begin{tabular}{|c|c|c|c|c|c|c|}
\hline 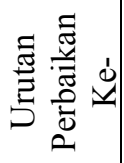 & 莞 & 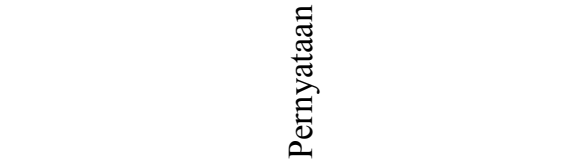 & $\begin{array}{l}\overrightarrow{4} \\
\frac{\pi}{Z} \\
\frac{\pi}{Z}\end{array}$ & 离导 & $\bar{\Xi}$ & $\ddot{\nabla}$ \\
\hline 1. & 21 & $\begin{array}{l}\text { Bengkel Yamaha Sumber Baru Motor Demangan } \\
\text { memiliki sparepart lengkap. }\end{array}$ & 14,23 & 21,99 & 7,76 & 73,55 \\
\hline 2 & 18 & $\begin{array}{l}\text { Peralatan yang digunakan Bengkel Yamaha } \\
\text { Sumber Baru Demangan lengkap. }\end{array}$ & 15,52 & 21,73 & 6,21 & 82,16 \\
\hline 3 & 5 & 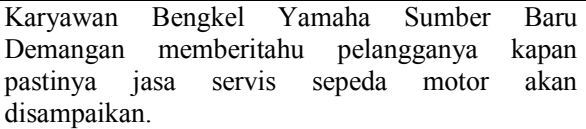 & 15,08 & 21,17 & 6,09 & 82,52 \\
\hline
\end{tabular}




\begin{tabular}{|c|c|c|c|c|c|c|}
\hline 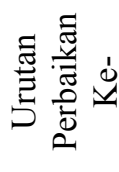 & 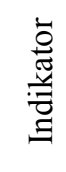 & 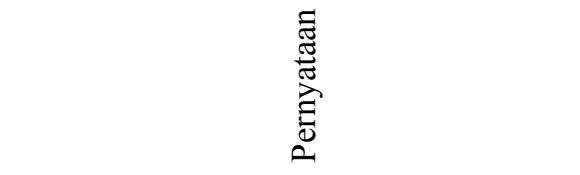 & 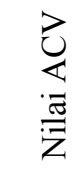 & 击己 & 昙导 & $\vec{Z}$ \\
\hline 4 & 8 & $\begin{array}{l}\text { Karyawan Bengkel Yamaha Sumber Baru } \\
\text { Demangan selalu siap dalam merespon permintaan } \\
\text { pelanggan. }\end{array}$ & 15,81 & 21,89 & 6,07 & 84,10 \\
\hline 5 & 6 & $\begin{array}{l}\text { Mekanik Bengkel Yamaha Sumber Baru } \\
\text { Demangan cepat dalam menyervis sepeda motor. }\end{array}$ & 15,94 & 21,58 & 5,64 & 85,58 \\
\hline 6 & 12 & $\begin{array}{l}\text { Karyawan Bengkel Yamaha Sumber Baru } \\
\text { Demangan senantiasa mampu menjawab } \\
\text { pertanyaan terkait dengan sepeda motor Yamaha. }\end{array}$ & 15,60 & 21,17 & 5,57 & 86,99 \\
\hline 7 & 15 & $\begin{array}{l}\text { Karyawan Bengkel Yamaha Sumber Baru } \\
\text { Demangan Motor selalu mengutamakan harapan } \\
\text { para pelanggan. }\end{array}$ & 15,60 & 21,12 & 5,52 & 87,44 \\
\hline
\end{tabular}

Sumber: Data diolah oleh peneliti

\section{Simpulan}

Berdasarkan hasil dan pembahasan yang telah diuraikan, dapat ditarik kesimpulan sebagai berikut:

1. Tingkat kesesuaian antara harapan (importance) pelanggan dan kinerja (performance) perusahaanterhadap kualitas jasa yang diberikan oleh Bengkel Yamaha Sumber Baru Motor Demangan, memiliki rata - rata tingkat kesesuaian dibawah $100 \%$ yaitu sebesar $88,35 \%$ yang berarti kualitas layanan Bengkel Yamaha Sumber Baru Demangan Motor kurang atau tidak memenuhi apa yang dianggap penting oleh pelanggan dan pelayanan belum memuaskan.

2. Metode Importance Performance Analysis (IPA) dan Potential Gain in Customer Value (PGCV) memberikan urutan prioritas perbaikan pada kuadran prioritas utama (kuadran A) dalam diagram kartesius dengan urutan sebagai berikut:

a. Bengkel Yamaha Sumber Baru Motor Demangan memiliki sparepart lengkap (P21).

b. Peralatan yang digunakan Bengkel Yamaha Sumber Baru Demangan lengkap (P18).

c. Karyawan Bengkel Yamaha Sumber Baru Demangan memberitahu pelangganya kapan pastinya jasa servis sepeda motor akan disampaikan (P5).

d. Karyawan Bengkel Yamaha Sumber Baru Demangan selalu siap dalam merespon permintaan pelanggan (P8). 
e. Mekanik Bengkel Yamaha Sumber Baru Demangan cepat dalam menyervis sepeda motor (P6).

f. Karyawan Bengkel Yamaha Sumber Baru Demangan senantiasa mampu menjawab pertanyaan terkait dengan sepeda motor Yamaha (P12).

g. Karyawan Bengkel Yamaha Sumber Baru Demangan Motor selalu mengutamakan harapan para pelanggan (P15).

\section{Saran}

Berdasarkan hasil dari penelitian yang dilakukan dapat dikemukakan beberapa saran untuk Bengkel Yamaha Sumber Baru Motor Demangan dan penelitian selanjutnya. Adapun saran yang disampaikan sebagai berikut:

1. Saran-saran perbaikan untuk dapat meningkatkan kualitas layanan yang diberikan untuk pihak bengkel Yamaha Sumber Baru Motor Demangan adalah sebagai berikut:

a. Melakukan pengoptimalan pemetaan rutin yang sudah ada terhadap kebutuhan sparepart.

b. Pihak perusahaan perlu melakukan perbaikan pada lift, perbaikan alat untuk menservis sepeda motor injeksi, perbaikan alat komputer dan peningkatan program untuk mendiagnosa sensor-sensor yang ada di sepeda motor.

c. Pihak perusahaan perlu memberikan perkiraan waktu pengerjaan pada pelanggan sehingga diperlukan kerjasama yang baik antara kepala mekanik dengan bagian pendaftaran.

d. Pihak perusahaan perlu memiliki inisiatif lebih untuk membantu para pelangganya dalam memecahkan masalah ketersedian sparepart.

e. Pengoptimalisasian alat agar waktu pengerjaan dapat dilakukan seefisien mungkin, manajemen bengkel Yamaha Sumber Baru Demangan Motor perlu mengadakan program pelatihan untuk mekanik dalam manajemen waktu, pihak manajemen perlu menerapkan sistem penghargaan (reward system) dalam bentuk kompensasi dan insentif finansial langsung serta mempertimbangkan penambahan jumlah mekanik. 
f. Pihak perusahaan perlu melakukan internal training untuk meningkatkan keahlian dan keterampilan mekanik.

g. Mengumpulkan info tentang kebutuhan pelanggan agar mayoritas harapan pelanggan dapat diketahui.

h. Survei kepuasan pelanggan hendaknya dilakukan secara periodik, sehingga harapan dan persepsi pelanggan dapat dipantau untuk memberi umpan balik atas perbaikan dan peningkatan kualitas jasa yang telah disesuaikan, terutama dalam persaingan bengkel yang semakin ketat. Kemudian sebaiknya pihak Bengkel Yamaha Sumber Baru Motor Demangan melakukan peningkatan kualitas jasa sesuai dengan usulan peningkatan kualitas jasa yang telah diprioritaskan karena indikator-indikator tersebut sangat diharapkan pelanggan sehingga pelanggan dapat terpuaskan.

2. Saran bagi peneliti selanjutnya yang tertarik untuk meneliti topik ini secara lebih mendalam, maka penulis akan menyarankan beberapa hal berikut:

a. Penelitian selanjutnya diharapkan lebih mengevaluasi pertanyaan-pertanyaan yang ada dalam kuisioner agar dapat mewakili secara tepat dimensi yang hendak diukur.

b. Peneliti selanjutnya diharapkan bisa mencari dimensi dan metode lain untuk mengukur kualitas jasa.

\section{DAFTAR PUSTAKA}

A. Zeithaml, V. Parasuraman, A. dan L. Berry L. 1985. Problems and Strategies in Services Marketing. Jurnal of Marketing. Vol. 49. (Spring).

Echdar, Saban. 2017. Metode Penelitian Manajemen dan Bisnis. Bogor: Ghalia Indonesia

Ghozali, Imam. 2010. Aplikasi Analisis Multivariate Dengan Program SPSS. Edisi keempat. Semarang: Universitas Diponegoro.

Hom, C. William. 1997. Make Customer Service Analyses a Little EasierWithThe PGCV Index. Journal of Quality Progress.

J. Supranto. 2006. Pengukuran Tingkat Kepuasan Pelanggan: Untuk Menaikkan Pangsa Pasar. Jakarta: Rineka Cipta.

Kasali, Rhenald. 2003. Manajemen Public Relations: Konsep dan Aplikasinya di 
Indonesia. Jakarta: PT. Pusaka Utama Grafiti.

Kotler, Philip dan Kevin Lane Keller. 2009. Manajemen Pemasaran. Jilid 1. Edisi 13. Jakarta: Erlangga

Kotler, Philip dan Kevin Lane Keller. 2009. Manajemen Pemasaran. Jild 2. Edisi 13. Jakarta: Erlangga.

Linus, David, Sarma, Tuti, Sinaga. Pujangkoro, Sugiharto. 2013. Perancangan Perbaikan Kualitas Pelayanan Dengan Menggunakan Analisis IPA Dan PGCV. E-Jurnal Fakultas Teknik Universitas Sumatera Utara Medan. Vol 1, No. 2, Maret 2013 pp. 15-20.

Martila, John, A. \& James, John, C. 1997. Importance - Performance Analysis. Journal of Marketing.

Nasution, M. N. 2004. Manajemen Jasa Terpadu. Bogor: Ghalia Indonesia.

Nugraha, Rizal, Ambar Harsono, dan Hari Adianto, 2014. Usulan Peningkatan Kualitas Pelayanan Jasa pada Bengkel "X" Berdasarkan Hasil Matrix Importance Performance Analysis. Jurnal Online Institut Teknologi Nasional. No.03. Vol.01. ISSN: 2338-5081.

Nugraha, Rizal, Ambar Harsono, dan Hari Adianto, 2014. Usulan Peningkatan Kualitas Pelayanan Jasa Rumah Sakit Ibu dan Anak dengan Menggunakan Metode Potential Gain in Customer Value. Jurnal Online Institut Teknologi Nasional. No.04.01. ISSN: 2338-5081.

Siregar, Syahrul Fauzi. Analisis Tingkat Kualitas Pelayanan Dengan Metode Index Potential Gain Customer Value (PGCV) Di Pt Bank Muamalat Indonesia Cabang Medan. Jurnal Sistem Teknik Industri. Volume 7, No. 4 Oktober 2006.

Sugiyono. 2018. Metode Penelitian Pendidikan Pendekatan Kuantitatif, Kualitatif, dan $R \& D$. Bandung: Alfabeta.

Tjiptono, Fandy. 2004.Manajemen Jasa. Edisi 2. Yogyakarta: ANDI.

Tjiptono, Fandy dan Gregorius Chandra. 2011. Service, Quality \& Statisfactio. Edisi 3. Yogyakarta: ANDI.

Fandy, Tjiptono, dkk. 2008. Marketing Scales. Yogyakarta: ANDI.

Sukwandi, Ronald dan Jufira. 2015. Penentuan Prioritas Perbaikan Kualitas Layanan TransJakarta dengan Menggunakan Metode IPA-PGCV. Jurnal Rekayasa Teknik Industri. Vol. 5, No. 2, 2015.

Woodruff, B. Robert. 1997. Customer Value: The Next Source for Competitive Advantage. Journal of the Academy of Marketing Science. Vol. 25, No. 2, pages 139-153.

Yazid. 2005. Pemasaran Jasa Konsep Dan Implementasi. Edisi 2. Yogyakarta: Ekonisia.

Zeithaml, Valarie \& Berry, Leonard \& V. Parasuraman, A. (1996). The Behavioral Consequences of Service Quality. Journal of Marketing. 


\section{Sumber Internet}

http://maps.google.com. 2018. "Ulasan Mengenai Harapan (Importance) Pelanggan Dan Kinerja (Performance) Terhadap Bengkel Yamaha Sumber Baru Motor Demangan". https://www.google.com/maps/place/Yamaha+ Sumber+ Baru+ Motor + Demangan/@7.7833861,110.3888749,17z/data=!4m7!3m6!1s0x2e7a 59d05 aaaaaab:0x212b6a306852b16f!8m2!3d-7.783386 1!4d110.3888749!9 $\mathrm{m} 1 ! 1 \mathrm{~b} 1$

(diakses tanggal 07, Febuari 2019)

www.bps.go.id. 2018. "Perkembangan Jumlah Kendaraan Bermotor Menurut Jenis, 1949-2017'.

https://www.bps.go.id/linkTableDinamis/view/id/1133

(diakses tanggal 07, Febuari 2019)

https://www.yamaha-motor.co.id/. 2019. "DEALER AND SERVICES”.

https://www.yamaha-motor.co.id/dealers

(diakses tanggal 07, Febuari 2019)

http://qmc.binus.ac.id. 2014. "GAP ANALYSIS"

http://qmc.binus.ac.id/2014/09/28/g-a-p-a-n-a-1-y-s-i-s/

(diakses tanggal 12, Juni 2019) 
